Western University

Scholarship@Western

Western Libraries Publications

Western Libraries

2018

Online Chat Reference: Question Type and the Implication for Staffing in a Large Academic Library

Debbie Meert-Williston

Western University, dmeertwi@uwo.ca

Rachel Sandieson

Western University,rmsandieson@gmail.com

Follow this and additional works at: https://ir.lib.uwo.ca/wlpub

Part of the Library and Information Science Commons

Citation of this paper:

Meert-Williston, Debbie and Sandieson, Rachel, "Online Chat Reference: Question Type and the Implication for Staffing in a Large Academic Library" (2018). Western Libraries Publications. 78.

https://ir.lib.uwo.ca/wlpub/78 
This is an Accepted Manuscript of an article published by Taylor \& Francis in The Reference Librarian on September 10, 2018, available online:

http://www.tandfonline.com/doi/full/10.1080/02763877.2018.1515688

\title{
Online Chat Reference: Question Type and the Implication for Staffing in a Large Academic Library
}

\author{
Debbie Meert-Williston \\ dmeertwi@uwo.ca \\ Rachel Sandieson \\ rsandies@uwo.ca
}

\begin{abstract}
This study investigated the types of questions asked in an academic online reference chat service to ascertain the level of library staff expertise needed to answer the questions. The transcripts from a large academic library were analyzed to determine both the type of questions asked, and the complexity of the reference questions asked. The data showed that $75 \%$ of the questions asked were non-reference, $17 \%$ of the questions asked were ready-reference, and $8.6 \%$ of the questions asked were in-depth or complex reference questions. Library staff with the capacity to answer both circulation and general reference questions would have the optimum level of expertise needed for staffing the types of questions asked through chat reference.

Keywords: chat reference, online reference, library staffing, librarian roles, library assistant roles
\end{abstract}


Online chat reference provision at academic universities has existed for many years and now is a commonplace service. Whether the service is provided in-house or by joining a consortium, libraries must decide how they will staff the service, and particularly which staff groups will be chat operators. Staffing of chat reference varies by institution but most commonly involves librarians, library assistants (or library technicians / paraprofessional staff) and other library staff, such as co-op students and interns. Some institutions rely on all of these positions to support their service, while others limit service provision by fewer or just one type of staff. In a time where efficient use of resources is critical, this is an important consideration. Library services and the roles of both librarians and library assistants are changing because of technology, the 21 st century knowledge economy, and budget considerations. Librarians have traditionally staffed physical reference desks and that naturally carried over into the online reference environment, but does that make sense?

While the decision on how to staff the service can be based on many factors, such as qualifications, experience, position description, resourcing capacity, etc., two key factors should be the type of questions being asked and the complexity/depth of those questions by users through the service. Once you know this you can use the information to help address the level and/or area of expertise or experience needed to answer those questions. To date there have been few studies that have looked at the type and depth of questions asked in a typical, post-secondary academic institution online chat reference service and yet doing so could provide key information needed in making staffing decisions for that type of service. This study analysed one year's worth of transcripts from a large Canadian university supporting eleven faculties with numerous departments and programs to determine the type and depth of questions asked through their online reference service. The transcripts also included questions asked by users at three 
colleges affiliated with the university. While questions were answered by both librarians and library assistants, the purpose of looking at the transcripts was to define what type of questions were being asked by library users, not who was providing the answers or the quality of answers. We looked at only online chat questions and did not compare to our in-person desk questions; as chat is a stand-alone service and questions may be unique to the medium in which it is offered, the interactions at an in-person reference service may bear little to no connection to what happens online. We used the transcripts from a large institution that would likely have reference interactions typical of other similar post-secondary institutions. The data collected could be used by similar institutions as one element that will help them to make decisions on how to staff their academic chat reference service, by using the data directly, or by providing a model to help them design an assessment exercise to gather their own institution-specific data.

The research questions to guide this study were:

1. What types of questions are being asked in online chat reference?

2. Given our library's service mandate, what type of staff group (librarian or library assistant) would be best to be chat operators, based on the questions asked?

\section{Literature Review}

\section{Staffing the Reference Desk}

Traditionally, librarians have staffed reference desks. From a 1988 article, Murfin and Bunge state "it is clear that academic libraries that use paraprofessional staff at the reference desk cannot routinely assume that such use is effective." (p. 14) Their study which assessed user satisfaction at the reference desk noted that patrons who received reference help from paraprofessionals were "more likely to feel that their assistance was less than fully 
knowledgeable staff." (p. 12)

Today, librarians are often pulled in many directions including areas such as collection development, information literacy instructional programming, and other tasks that benefit libraries and their institutions (Courtney, 2001; Ryan, 2008). Because of this, the nature of their work has changed over the years and similarly, with a move to digital resources and circulation systems, the nature of library assistants' work has changed as well. Now it is common to see a physical reference desk staffed by a mix of librarians and library assistants or by only library assistants. Librarians often acquire reference training as part of their formal education, yet this training can be provided to other library staff needing to perform reference duties. With training that covers policies, procedures, service philosophies, building tours, overviews of collections and most importantly, reference interview skills, library assistants can perform reference tasks (Courtney, 2001). It is also beneficial for library assistants to understand when to refer questions to librarians and when subject-specific knowledge or advanced information literacy skills are required to answer a question (Pedzich, 2000). Training and development is the key to the transfer of this area of library work from librarian to library assistant, as Tin and Al-Wawamdeh (2002) state:

Nonetheless, in this knowledge economy, one must wake up to the technology call. Nothing should remain stagnant. Everything moves on and changes, be it for better or worse. The same applies to reference services. When the professional librarians have to move on to provide more value-added services, the paraprofessionals have to move up to supplement the role in reference which the professionals have performed for years. There should be sufficient training so that the paraprofessionals can be competent and confident in providing the reference services. For the issue on paraprofessionals at the reference 
desk, one should no longer harp on as to 'whether' they should be allowed, but 'how' to train and equip them with all necessary competencies. (p. 342)

Not only do models that include paraprofessionals on the desk allow them to broaden their skills and increase professional development (Courtney, 2001), it gives them increased job satisfaction in answering challenging questions and engaging with users (Tin \& Al-Hawamdeh, 2002).

Furthermore, it allows for librarians to attend to the other demands of their jobs.

\section{Staffing the Virtual Reference "Desk"}

Does the medium of reference matter when it comes to how it is staffed? Unlike traditional in-person reference, chat reference is sometimes considered optional for staff, a duty performed only by library staff who may volunteer to do so (Matteson, Salamon, \& Brewster, 2011). This often results in insufficient training and disagreements on the impact of librarian workload due to chat (Matteson, et al., 2011). However, research shows that there are a mix of staffing models being used: librarians only as chat operators or librarians and library assistants working together as operators. Both refer more challenging questions, or questions that require in depth subject knowledge, to specialist librarians when needed (Carlson, Nicol, \& Crook, 2013). Another challenge with staffing online reference is appealing to users who want subjectspecific support. These users tend to avoid chat altogether and simply go to the physical library that is associated with their area of study, since when they do utilize the chat service, they are often be referred to that library anyway (Armann-Keown, Cooke, \& Matheson, 2015). Further, staff who do not have access to all library resources (i.e., circulation software and policies) face the challenge of providing a consistent level of service which impacts users since "differences in staff competencies, subject knowledge and experience will impact the success of each reference transaction and patron satisfaction.” (Armann-Keown, et al., 2015, p. 657) 
Both Keyes and Dworak (2017) and Lux and Rich (2016) looked at library chat services staffed by undergraduate students. Lux and Rich found that while both students and librarians gave a similar number of complete answers to questions ( $77 \%$ for students and $82 \%$ for librarians) that librarians received higher scores from users in terms of how users rated the service (78\% good or excellent scores for librarians compared to $58 \%$ for students). Keyes and Dworak (2017) noted that after analyzing transcripts, student staffers likely needed further training regarding referrals, providing sources, and signing off, yet "students also did better than anticipated at providing instruction." They noted that "given the changing role of the academic library and the resulting trend toward a tiered reference model, it is our conclusion that having well-trained undergraduate students staff chat reference is a viable, and even desirable, option."

\section{Should the Nature of Questions Impact Reference Staffing, No Matter the Medium?}

In a 2008 study, Ryan noted that out of 32.4 transactions at the physical reference desk per day, 20.8 were directional, machine, and technology questions, 8 other non-research questions, and only 3.6 questions research in nature. She further noted that " $89 \%$ of the reference transactions in this study could be handled by students or staff trained in basic knowledge of the library's electronic resources, hardware and software issues, and procedures and policies, with an occasional referral to a librarian."

Bishop and Bartlett (2013) analyzed approximately 1,800 reference questions in-person, over the phone, and electronically through chat and email to understand the types of questions asked. The majority (83.7\%) of questions were location-based (being directional or informational) with only $16.3 \%$ subject-based reference questions. They believe that subjectbased research questions should be answered by librarians, as these questions "still require quality service from trained professionals regardless of where they are physically located." With 
similar numbers, Fuller and Dryden (2015) looked at over 3,000 questions and noted that "the largest number of questions were categorized as Access (34\%), with Information/Direction (24\%), Other (23\%), and Subject Search/Research (15\%) following. Only 4\% of the questions were identified as Ready Reference.”

Côté, Kochkina, and Mawhinney (2016) examined a sample of chat questions and found that only $17 \%$ of chat questions were reference and $98 \%$ of questions required basic or intermediate -level knowledge, with only $2 \%$ requiring advanced knowledge, requiring subject expertise. Their model is staffed by librarians only and they state, "The analysis of the virtual reference transactions shows a relatively low number of referrals, which suggests that librarians have a level of expertise that is more than adequate to answer most of the questions." They also note that it might be more appropriate to keep librarian-only staffing as chat transactions could present themselves as teachable moments for information literacy (Côté, et al., 2016). But will a student looking for help on booking a study room stay in a chat longer to get information literacy help if they did not really need or want it? They also noted that with only librarians staffing chat, there were fewer referrals, "which suggests that librarians have a level of expertise that is more than adequate to answer most of the questions." (Côté, et al., 2016) However, with adequate reference training, could library assistants fully answer questions as well?

With an overall decline in reference questions being asked, and reference questions becoming less complex (Dinkins \& Ryan, 2010), can the nature of questions help influence if librarians or library assistants should be staffing reference online? Our research aims to look at a year's worth of chat reference transcripts to help address the question of virtual reference staffing. 


\section{Methods}

One academic year of transcripts $(n=2,734)$ were collected from a large $(34,062$ FTE), Canadian post-secondary institution, from September 2013 to August 2014 (Western University, 2014; Brescia University College, 2014; Huron University College, 2014; King's University College, 2014). The institution and its affiliated colleges support the faculties of Engineering, Medicine, Music, Business, Education, Arts and Humanities, Social Science, Law, Science, Health Sciences, and Information and Media Studies, Theology, Social Work, Social Justice and Peace, and Food Science \& Nutrition. The transcripts were collected from a consortial chat reference service that the home institution participated in and all the transcripts of the questions asked by the students attending the home institution and affiliated colleges were collected, regardless of whether a home institution staff member or consortial staff member (staff from another institution in the consortium or a service intern) answered the question.

The transcripts were anonymized by two staff members in the home institution's Office of the Chief Librarian so that no identifying factors regarding the student or staff member involved in the transaction remained. The transcripts were coded by one of the authors of this study using a coding tool created by the authors (see Appendix A). The coding tool was created to ascertain the type and complexity or depth of the question being asked by the user (see Appendix A for definitions). Transcripts that fit under multiple question types were coded under the most prominent type that was asked. For example, a reference question about finding books on an essay question might include the operator answering where to find the books in the library, but the reference element is the focus of the question. 


\section{Results}

The following figures display the data displayed by percentage and the raw data.

Figure 1 and Table 1 display all question types, Figure 2 and Table 2 display the breakdown of Service questions only, and Figure 3 and Table 3 display the breakdown of Reference questions only.

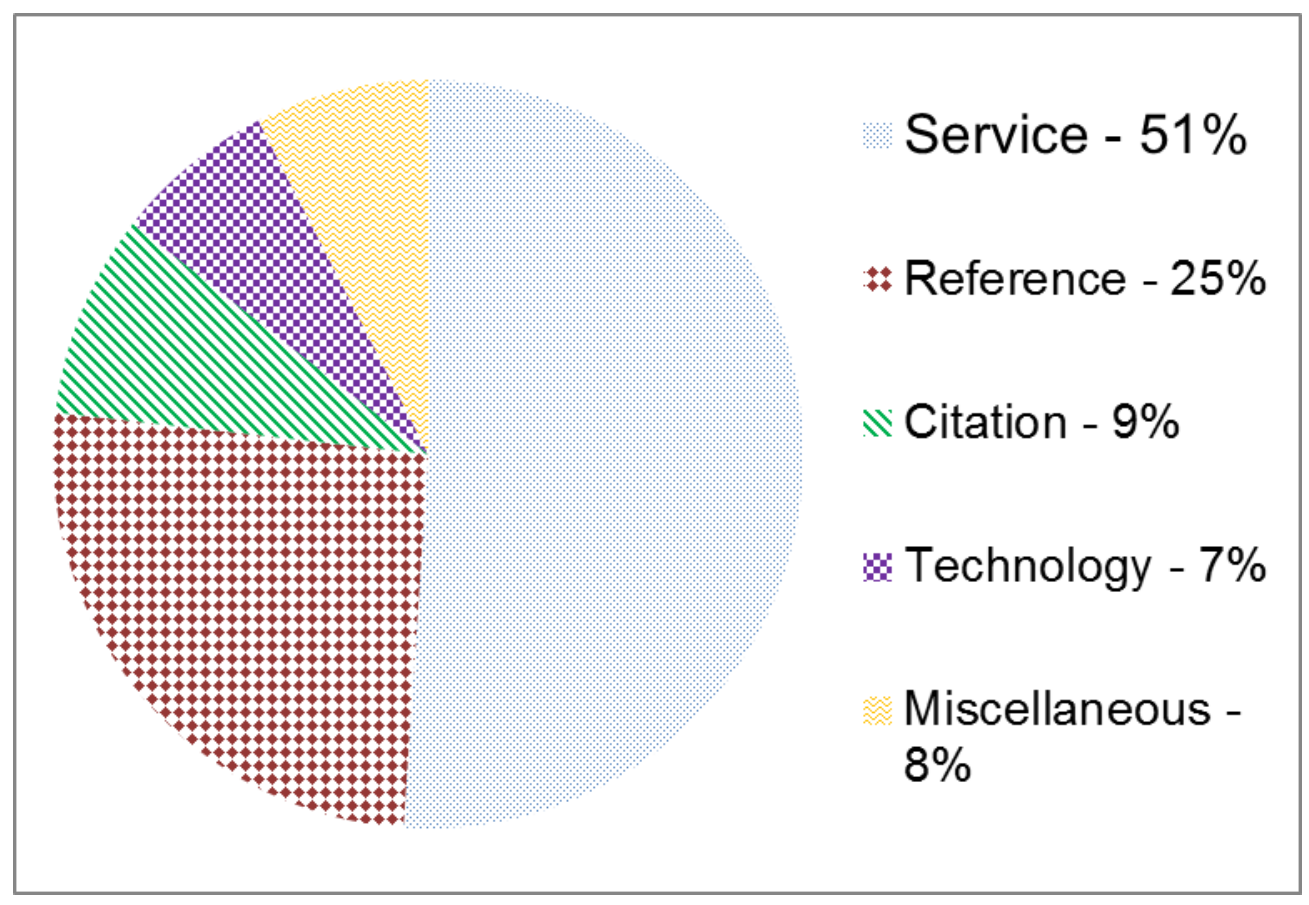

(Figure 1 - Total Question Type by Percentage)

\begin{tabular}{|ll|}
\hline Type of Question & Number of Questions $(\mathrm{n}=2734)$ \\
\hline Service & 1396 \\
Reference & 703 \\
Citation & 240 \\
Technology & 190 \\
Miscellaneous & 205 \\
\hline
\end{tabular}

(Table 1 - Total Question Type by number of transcripts) 


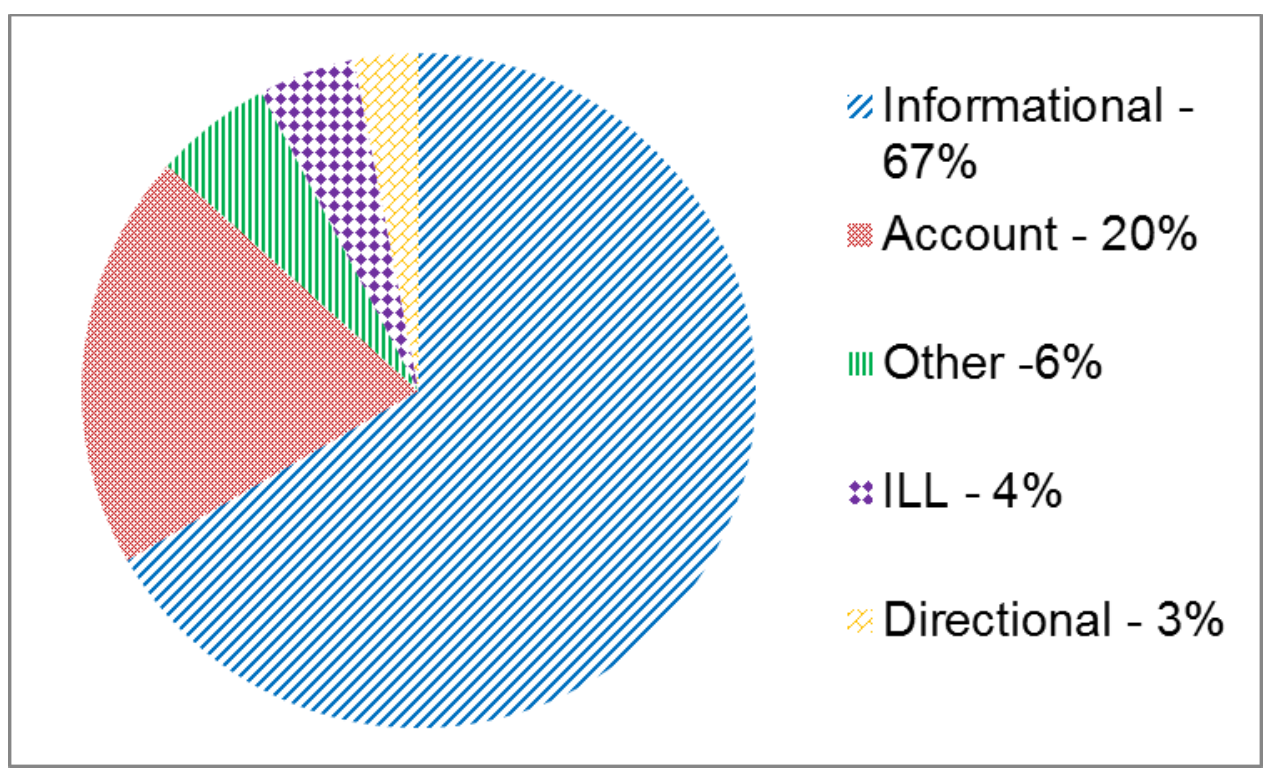

(Figure 2 - Service Question Type by Percentage)

\begin{tabular}{|ll|}
\hline Type of Service Question & Number of Questions $(\mathrm{n}=1396)$ \\
\hline Informational & 930 \\
Account & 279 \\
Other & 79 \\
ILL & 65 \\
Directional & 43 \\
\hline
\end{tabular}

(Table 2 - Service Question Type by number of transcripts)

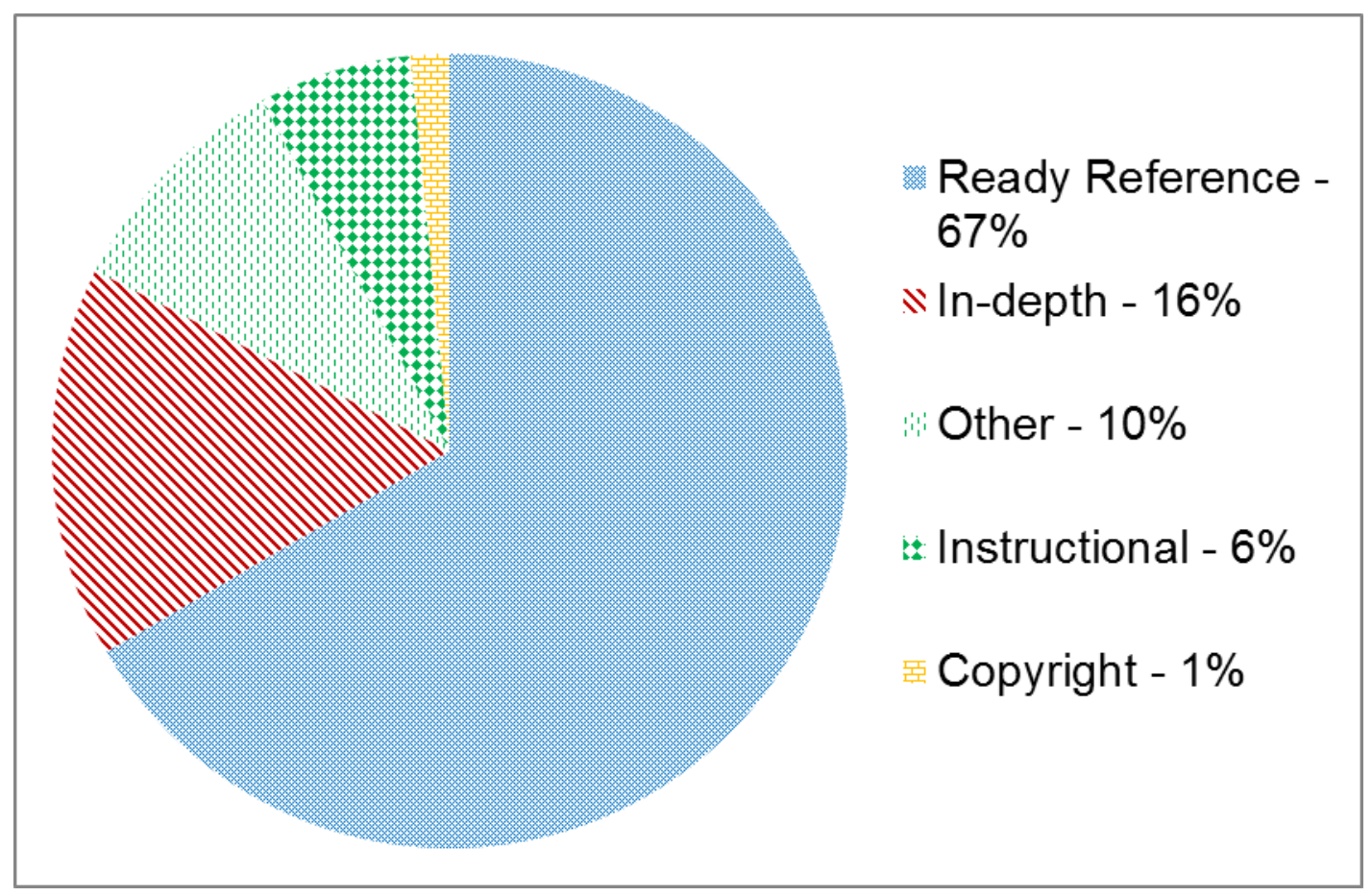


(Figure 3 - Reference Question Type by Percentage)

\begin{tabular}{|ll|}
\hline Type of Reference Question & Number of Questions $(\mathrm{n}=703)$ \\
\hline Ready Reference & 468 \\
In-depth & 112 \\
Other & 68 \\
Instructional & 44 \\
Copyright & 11 \\
\hline
\end{tabular}

(Table 3 - Reference Question Type by number of transcripts)

The results can be viewed in a few different ways, depending on the way to approach the question categories with regards to complexity, level of knowledge needed to answer them, and level of service an institution wants to provide through online library chat. For example, there were 240 questions about citation. Is the mandate of your library chat service to provide answers on how to cite sources, or to guide users to resources where they can find and apply citation rules and practices? Another example would be what is categorized in this study as Instructional Reference; does staff at other service points approach questions as teachable moments or is the role of the staff member to provide the user's immediate needs only? A common question seen in chat is that users are looking for a full-text document of an article; would the staff member simply provide this document or should they be instructing the user on how to find the document? Depending on how you view the intention of your library chat service, which may or may not be different from your physical service desks, you could choose to group the question categories differently.

If we look at the results with the intention of providing as complete as possible reference interactions, including taking in-depth, instructional, citation, and copyright questions to an expert level of providing answers, and not just guiding the user to resources, then the results show that out of 2,529 questions ( $\mathrm{n}=2,734-205$ miscellaneous questions removed), 475 questions (19\%) or about 1 in every 5 questions, that were asked needed a high level of library 
expertise to answer them. If the intention of your library chat service was more directional with regards to questions about citation and copyright, it would bring the number of questions needing a high level of library expertise to answer them, down to about $9 \%$, or about 1 in every 10 questions.

\section{Discussion}

Even if the level of reference expertise an institution wants to provide to their users is high, the data from this study shows that only about 1 in 5 questions needs that expertise. In an institution that has a large number of staff with varying levels of expertise, they may not want to have their staff with the highest level of expertise spending a lot of time providing a service where that expertise is needed only $20 \%$ of the time. However, they may also not want staff without a lot of expertise providing service when they are unable to answer about $20 \%$ of the questions. For a large institution with a large number of staff with varying levels of expertise, having staff with a mid-level of expertise may prove to be the most effective and efficient way to staff the service. Obviously, for smaller institutions, this may not be an option. However, if you are able to staff your service with mid-level expertise, what then happens with those questions that require a high level of expertise? The most common way to address those questions is by referring or triaging the patron directly to a librarian/staff member with the expertise to directly support their question or need. This could mean that the patron does not get a high level of assistance in the moment, and this may or may not adhere to the mandate for providing service. An institution would need to weigh the variables of cost versus outcome, and decide based on their mandate, policies, resources, patron expectations, and what they would consider reasonable/acceptable levels of service. 
So why don't the majority of questions coming through the chat service need a high level of expertise? There could be many reasons why this is the case. Users may perceive an online service as a place to go for quick questions, and they take their more in-depth questions to their subject library or librarian. It could also be that any prominent library "help" option is going to get asked all types of questions, and users may or may not acknowledge or understand our definitions of "librarian" or "reference" if and when we use those anyway. It could also just simply be that there are more service questions from users than reference questions.

We did not compare the virtual reference or service questions to in-person questions in this study, particularly on a combined service/reference desk, but that would be a telling thing to do. It would be interesting to see if the types of questions asked face-to-face differ from the questions users ask in an online environment, and if the responses differ, as well. This would be a study that would be broader in context and more in depth; it would need to take many factors into consideration, particularly the limitations and advantages of virtual versus physical services, and account for those variables in the results. Therefore, in this study we focused on the online chat questions only, anticipating that the medium itself could influence the type of questions asked. For example, one of the most common service questions asked was a user looking for a full-text pdf version of a journal article. Given that this is a question about a virtual resource, are we more likely to see this type of question asked in a virtual space?

Depending on the service philosophy of the institution, resources available, the levels of staffing and expertise available, and the types and complexity of questions being asked by users, thoughtful decisions should be made by institutional libraries about which staff members would be the best fit for any particular service, from both an expertise and a resource diligent perspective. It could be an exercise in both efficacy and efficiency for institutions to look at how 
many librarian versus library assistant hours they are allocating to their virtual reference service compared to the type and complexity of questions asked.

\section{Conclusion}

For the institution in this study, with their service mandate and the resources available, we believe the data indicates that the most efficient and effective way to staff their library chat service would be with library assistants that have the service capacity and expertise to answer both circulation and general reference questions, and the ability to effectively triage questions needing a higher level of support to the appropriate subject or specialty service librarian or professional.

Through this study we hope that other institutions can get a big picture idea of what types of questions are being asked through this type of service at a typical, large academic institution library. With that information they can start asking questions about their own needs, service mandate, resources, and the capacity and expertise of their staff, to determine how they can approach staffing an online chat service at their own institution.

Note: We would like to thank Megan Sioui, BA, MLIS, and Alex Korovessis, BSc, MLIS, for their help in anonymizing all of the chat transcripts. 


\section{References}

Armann-Keown, V., Cooke, C. A., \& Matheson, G. (2015). Digging Deeper into Virtual Reference Transcripts. Reference Services Review, 43(4). 656-672.

Bishop, B. W., \& Bartlett, J. A. (2013). Where do we go from here? Informing academic library staffing through reference transaction analysis. College \& Research Libraries, 74(5), 489.

Brescia University College. (2014). Common University Data Ontario Brescia University College 2013. Retrieved from http://brescia.uwo.ca/about/wpcontent/uploads/sites/3/delightful-downloads/2014/06/Brescia-CUDO-2013.pdf

Courtney, N. (2001). Evaluating the use of paraprofessionals at the reference desk. College \& Undergraduate Libraries, 8(1), 27-35.

Côté, M., Kochkina, S., \& Mawhinney, T. (2014). Do you want to chat? Reevaluating organization of virtual reference service at an academic library. Reference \& User Services Quarterly, 56(1), 36-46.

Dinkins, D., \& Ryan, S. M. (2010). Measuring Referrals: The Use of Paraprofessionals at the Reference Desk. Journal of Academic Librarianship, 36(4), 279-286.

Fuller, K., \& Dryden, N. H. (2015). Chat reference analysis to determine accuracy and staffing needs at one academic library. Internet Reference Services Quarterly, 20, 163181. doi:10.1080/10875301.2015.1106999

Huron University College. (2014). Total Enrolment by Program. Retrieved from http://www.huronuc.on.ca/Assets/A6TotalEnroll.pdf

Keyes, K., \& Dworak, E. (2017). Staffing chat reference with undergraduate student assistants at an academic library: A standards-based assessment. The Journal of Academic Librarianship, 43, 469-478. 
King's University College. (2014). Common University Data Ontario - 2013. King's University College at Western University. Retrieved from https://www.kings.uwo.ca/about-kings/who-we-are/facts/cudo/cudo-2013/

Lux, V. J., \& Rich, L. (2016). Can student assistants effectively provide chat reference services? Student transcripts vs. librarian transcripts. Internet Reference Services Quarterly, 21(34), 115-139. doi:10.1080/10875301.2016.1248585

Matteson, M. L., Salamon, J., \& Brewster, L. (2011). A Systematic Review of Research on Live Chat Service. Reference \& User Services Quarterly, 51(2). 172-189.

Murfin, M. E., \& Bunge, C. A. (1988). Paraprofessionals at the Reference Desk. Journal of Academic Librarianship, 14(1), 10-14.

Nicol, E. C., \& Crook, L. (2013). Now it's Necessary: Virtual Reference Services at Washington State University, Pullman. Journal of Academic Librarianship, 39(2), 161-168.

Pedzich, J. (2000). Paraprofessionals at the reference desk: Training and documentation. Legal Reference Services Quarterly, 18(2), 91-99.

Ryan, S. M. (2008). Reference Transactions Analysis: The Cost-Effectiveness of Staffing a Traditional Academic Reference Desk. Journal of Academic Librarianship, 34(5), 389399.

Tin, K. L., \& Al-Hawamdeh, S. (2002). The changing role of paraprofessionals in the knowledge economy. Journal of Information Science, 28(4), 331-343.

Western University. Full-Time Enrolment 2013-14. (2014). Retrieved from http://www.ipb.uwo.ca/documents/2014 full time enrolment.pdf 